\title{
Physiological maturation stage of cervical vertebrate index in cleft lip/palate and non-cleft lip/palate patients
}

\author{
Wenti Komala*, Endah Mardiati**, Eky Soeria Soemantri**, Isnaniah Malik ${ }^{* *}$ \\ *Orthodontic Specialist Program, Faculty of Dentistry, Padjadjaran University, Bandung, Indonesia \\ **Department of Orthodontics, Faculty of Dentistry, Padjadjaran University, Bandung, Indonesia \\ *JI Sekeloa Selatan 1, Bandung, West Java, Indonesia; email: wentyk90@gmail.com
}

Submitted: $18^{\text {th }}$ September 2017; Revised: 23 ${ }^{\text {rd }}$ July 2018; Accepted: $2^{\text {th }}$ September 2018

\begin{abstract}
Cleft lip and palate is one of the most common congenital anomalies. Cleft lip and palate patients encounter growth problems in lip and palate area, although their overall growth and development remains unknown. Cervical vertebral maturation are indicators of physiological maturation used in interceptive treatment and orthognathic surgery. The present study aims to determine physiological maturation stage of cervical vertebrae maturation index in cleft and non-cleft patients. Lateral cephalogram of 26 cleft patients and 27 non-cleft patients with a range of chronological age from 8-16 years old were involved. The cervical vertebrae maturation were analyzed in six stages of cervical vertebrae maturation method of Hassel and Farman. Data were analyzed using t-test ( $\leq \leq 0.05)$. The result shows that physiological maturation stage of cervical vertebrae maturation index in cleft and non-cleft patients has no significant difference in stage acceleration $(p=0.38)$, stage transition $(p=0.41)$ and deceleration $(p=0.39)$. Likewise, there is no significant difference in physiological maturation stage of cervical vertebrae maturation index between cleft and non-cleft patients.
\end{abstract}

Keywords: cleft lip and palate; Hassel and Farman's method; maturation index

\section{INTRODUCTION}

Malocclusion is a form of deviation of misalignment from the standard and generally accepted teeth arrangement. An occlusion is said to be normal if the teeth arrangement of the two dental arches is regular and can relate the upper teeth and lower teeth correctly as the jaws close. ${ }^{1}$ The most common congenital anomalies are cleft lip and palate abnormalities. International data noted that during the course of 2002 to 2006, the prevalence of cleft lips averaged 8 per 10,000 births worldwide. ${ }^{2}$

Deficiency of maxillary growth in cleft lip and palate patients leads to third class malocclusion. Therefore, it is vital to determine the right growth period for cleft lip and palate patients, since each treatment shall be adjusted to the patient's skeletal age, such as dentofacial orthopedic devices during patients' growth and surgical orthodontic treatment once they achieve adulthood. ${ }^{3}$

The current research delineates that patients with cleft lip/palate abnormalities experience different growth rate from the non-cleft lips/palate patients. Given such background, the researchers are interested in examining the physiological maturation stages of cervical vertebral index in cleft lip/palate patients at the orthodontics clinic of Faculty of Dentistry Padjajaran University Bandung.

\section{MATERIALS AND METHODS}

This is a descriptive comparative study using total sampling and involving the subjects of all cleft lip/ palate patients and non-cleft lip/palate patients at the orthodontics clinic of Faculty of Dentistry Padjajaran University with chronological age of 8-16 years. Research, screening and orthodontics clinic were conducted from March to May 2017. The study used the 6 stages of physiological maturation based on Hassel and Farman's methods, namely initiation, acceleration, transition, deceleration, maturation and completion based on $\mathrm{x}$ - cephalograms taken in the department of radiology Faculty of Dentistry Padjajaran University. The study used total 
sampling technique, by which the samples were selected based on inclusion criteria and exclusion criteria. The inclusion criteria for this sample were lateral cephalogram data at the cleft center of Dental Hospital Padjajaran University, which were in the chronological age range of 8-16 years, with clearly visible $\mathrm{C} 2$, C3, C4 cervical vertebrae on the lateral cephalogram, lateral cephalogram photos accompanied by the patient's name and date of birth, and carried out in the department of radiology of the faculty of dentistry Padjajaran University. Screening templates were carried out at 6 stages of cervical vertebra maturation using Hassel and Farman's methods. The researchers then screened all study samples of cleft lip and palate patients and non-cleft lip and palate patients using a $4 \mathrm{H}$ pencil above the negatoscope and compared the result with the standard plastic template made previously.
Data were analyzed by paired $T$ tests to compare the physiological maturation based on cervical vertebral indexes of cleft-lip palate and non-cleft lip-palate patients.

\section{RESULTS}

This research was conducted with a total sample of 26 cleft lip and palate and 27 non-cleft lip and palate patients' cephalogram. The subjects of the study were lateral cephalograms of cleft lip and palate patients at the RSGM UNPAD Cleft Center and non-cleft lip and palate patients at the UNPAD Faculty of Dentistry with chronological ages of 8-16 years who met the inclusion criteria. The subjects of this study amounted to 53 lateral cephalograms consisting of cleft lip and palate patients and non cleft-lip and palate patients.

Table 1. The chronological age of cleft lip and palate patients based on the maturation stage of the cervical vertebra.

\begin{tabular}{cccc}
\hline No & $\begin{array}{c}\text { Maturation stage of cleft lip } \\
\text { and palate patients }\end{array}$ & $\begin{array}{c}\text { Number } \\
\text { (person) }\end{array}$ & $\begin{array}{c}\text { Average chronological age } \\
\text { (year) }\end{array}$ \\
\hline 1 & Stage 1 & 7 & 8.86 \\
2 & Stage 2 & 9 & 9.56 \\
3 & Stage 3 & 5 & 12.4 \\
4 & Stage 4 & 3 & 13.67 \\
5 & Stage 5 & 1 & 15 \\
6 & Stage 6 & 1 & 16 \\
& Total & 26 & \\
\hline
\end{tabular}

\section{Description:}

Stage $1=$ Initiation Stage 2 = Acceleration Stage $3=$ Transition
Stage $4=$ Deceleration

Stage $5=$ Maturation

Stage $6=$ Completion

Table 2. The chronological age of non-cleft lip and palate patients based on the cervical vertebral maturation stage.

\begin{tabular}{cccc}
\hline No & $\begin{array}{c}\text { Maturation stage of non-cleft } \\
\text { lip and palate patients }\end{array}$ & $\begin{array}{c}\text { Number } \\
\text { (person) }\end{array}$ & $\begin{array}{c}\text { Average chronological age } \\
\text { (year) }\end{array}$ \\
\hline 1 & Stage 1 & - & - \\
2 & Stage 2 & 3 & 9 \\
3 & Stage 3 & 5 & 12 \\
4 & Stage 4 & 8 & 13.1 \\
5 & Stage 5 & 4 & 13 \\
6 & Stage 6 & 7 & 15.71 \\
& Total & 27 & \\
\hline
\end{tabular}

Description:

$\begin{array}{ll}\text { Stage } 1=\text { Initiation } & \text { Stage } 4=\text { Deceleration } \\ \text { Stage } 2=\text { Acceleration } & \text { Stage } 5=\text { Maturation } \\ \text { Stage } 3=\text { Transition } & \text { Stage } 6=\text { Completion }\end{array}$




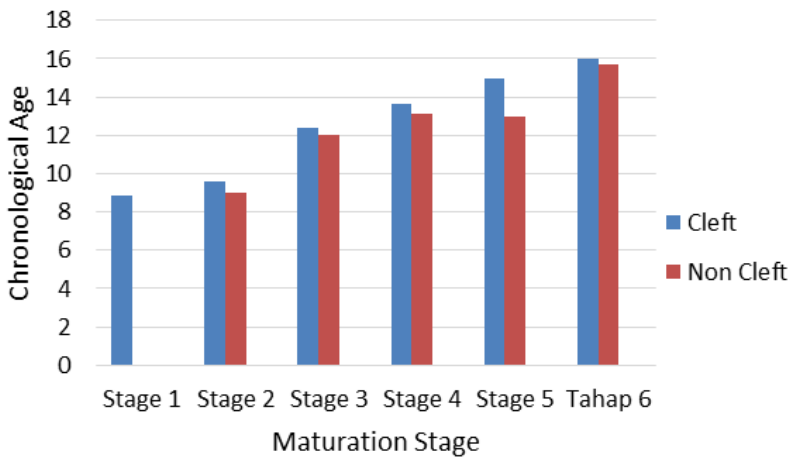

Figure 1. Average Chronological age based on cervical vertebral index in cleft lip and palate patients and non-cleft lip and palate

Table 3. Difference test of average chronological age at each stage of physiological maturation based on cervical vertebrae index in cleft lip and palate patients and non-cleft lip and palate patients

\begin{tabular}{|c|c|c|c|c|c|}
\hline \multicolumn{2}{|c|}{ Maturation stage } & \multirow{2}{*}{$\begin{array}{l}n \\
7\end{array}$} & \multirow{2}{*}{$\begin{array}{c}\text { Standard } \\
\text { deviation } \\
-\end{array}$} & \multirow{3}{*}{$\begin{array}{c}t / Z \\
-\end{array}$} & \multirow{3}{*}{$\begin{array}{c}\text { p-value } \\
\text { - }\end{array}$} \\
\hline \multirow{2}{*}{1} & C & & & & \\
\hline & $\mathrm{NC}$ & 0 & - & & \\
\hline \multirow{2}{*}{2} & C & 9 & \multirow{2}{*}{1.33} & \multirow{2}{*}{0.29} & \multirow{2}{*}{0.39} \\
\hline & $\mathrm{NC}$ & 3 & & & \\
\hline \multirow{2}{*}{3} & C & 5 & \multirow{2}{*}{1.18} & \multirow{2}{*}{0.21} & \multirow{2}{*}{0.42} \\
\hline & $\mathrm{NC}$ & 5 & & & \\
\hline \multirow{2}{*}{4} & C & 3 & \multirow{2}{*}{1.23} & \multirow{2}{*}{0.42} & \multirow{2}{*}{0.39} \\
\hline & $\mathrm{NC}$ & 8 & & & \\
\hline \multirow{2}{*}{5} & C & 1 & \multirow{2}{*}{ - } & \multirow{2}{*}{-} & \multirow{2}{*}{ - } \\
\hline & $\mathrm{NC}$ & 4 & & & \\
\hline \multirow{2}{*}{6} & C & 1 & \multirow{2}{*}{ - } & \multirow{2}{*}{ - } & \multirow{2}{*}{ - } \\
\hline & $\mathrm{NC}$ & 7 & & & \\
\hline
\end{tabular}

Description:

$\mathrm{C}=\mathrm{Cleft}$

$N C=$ Non-Cleft

$p<0.05$

\section{DISCUSSION}

This research was conducted by taking secondary data of lateral cephalogram X-ray from cleft center of Dental Hospital and orthodontics clinic of Faculty of Dentistry, Padjajaran University. This research excluded subjects younger than 8 years, but covered those in the age of growth and development. Wong et al explained that the cervical vertebral method is not sensitive to detect growth maturity outside the period of growth and development. Beyond age ranges reduce the accuracy of the cervical vertebrae method and prevents it from accurately detecting changes that occur in skeletal maturation. ${ }^{4}$
Statistical analysis in this study can only be done in stage 2 (acceleration), stage 3 (transition), and stage 4 (deceleration) because the age of the samples in cleft lip and palate patients and non-cleft lip and palate patients is uneven. In the group of cleft lip and palate patients only 1 person reached stage 5 (maturation) and stage 6 (completion), while in the group of non-cleft lip and palate patients no sample reached stage 1 (initiation), making it difficult to conduct statistical analysis. Samples of cleft lip and palate patients were mostly of 8-11 years of age while non-cleft lip and palate patients were mostly aged $11-16$ years. Patients who come to the left center of dental hospital Padjajaran University are generally treated at an early age so that their medical records from an early age are well documented. On the other hand, patients of the orthodontics department of the faculty of dentistry Padjajaran University come to the clinic when they are 11-16 years old.

This study indicates no significant differences in the stages of acceleration, transition, and deceleration. This shows that cleft lip and palate patients and non-cleft lip and palate patients have achieved the same maturation stage. Lee et. al. evaluated the growth status of cleft lip and palate patients at the age of 0-4 years and concluded that at the age of 0-4 years, it will be more difficult for the babies with cleft lip and palate abnormalities to get food intake, which disrupts their growth. However, once they receive surgical treatment at the age of 25,5 months, they will catch up with the normal growth so that they will no longer suffer from growth slowdown. ${ }^{5}$ Research conducted by Ranalli and Mazaheri (1975) concluded that the growth slowdown of cleft lip and palate patients occurs in their first 3 years of age, but they will have growth increase and reach the same growth rate as the common children of the same age. ${ }^{6}$ Overall, there is no significant difference in growth and development of cleft lip and palate patients from that of normal patients. $^{7}$

The results of the above studies are different from those conducted by Sun and Li (2013), which delineated that lip and palate cleft patients experiencing more growth and development 
slowdown than non-cleft lip and palate patients, especially in stage 2 (acceleration) and stage 3 (transition). ${ }^{8}$ However, as seen from the age averages in stage 2 (acceleration) and stage 3 (transition) in this study, it is apparent that cleft lip and palate patients reached stage 2 and stage 3 in a slower pace than non-cleft lip and palate patients even though the mean difference is not significant. Retardation of growth and development in cleft lip and palate patients is caused by difficulties in getting food intake and the higher frequency of infection. ${ }^{9}$ This study is different from the research conducted by Poonsak (2013) due to variations in race, environmental conditions, research methodology, type of cleft, sex, and various growth indicators. ${ }^{3}$

Treatment for growth modification can be performed on cleft lip and palate patients before they complete their puberty levels. The research revealed that there was a similar pattern of growth and development between cleft lip and palate patients and non-cleft lip and palate patients. Therefore, the peak of puberty in cleft lip and palate female patients and non-cleft lip and palate female patients can refer to the peak age of puberty growth in Indonesian women in general, namely of 12.3 years and men of 13.27 years. ${ }^{10,11}$ The research reveals that the average peak growth of cleft lip and palate patients were 9.6-12.4 years and non cleft lip and palate patients were 9-12 years.

The results of this study can be used as a reference in determining the right time for modification treatments. Cleft lip and palate patients have a tendency towards maxillary growth deficiency so that when referred to an orthodontist before the peak of puberty growth ends, they can have modification treatments for growth. However, once they complete the peak growth of puberty, they will require more complex treatment of orthognathic surgery.

\section{CONCLUSION}

The physiological maturation stages in cleft lip and palate patients and non-cleft lip and palate patients will be the same in stage 2 (acceleration), 3 (transition), and 4 (deceleration). The cleft lip and palate patients who have received surgical treatment will normally experience a catch-up growth and development because they receive sufficient intake of nutrients that prevent growth and development slowdown compared with normal patients.

\section{REFERENCES}

1. Vigni A, Anindita $P$, Paulina. Gambaran maloklusi dengan menggunakan HMAR pada pasien di Rumah Sakit Gigi dan Mulut Universitas Sam Ratulangi Manado. Jurnal e-Gigi. 2014. 2: 2.

2. Tanaka SA, Mahabir RC, Jupiter DC, Menesez JM. Updating the epidemiology of cleft lip with or without cleft palate. Plast Reconstr Surg. 2012; 129(3): 511-518.

3. Poonsak P, Godfrey K, Manosudprasit $M$, Wangsrimongkol $T$, Leelasinjaroen $P$. A Comparison of cervical vertebral maturation assessment of skeletal growth stages with chronological age in thai between cleft lip and palate and non-cleft patients. J Med Assoc Thai. 2013; 96(4): S9-S18.

4. Wong RW, Alkhal HA, Rabie AB. Use of cervical vertebral maturation to determine skeletal age. Am J Orthod Dentofacial Orthop. 2009; 136: 484-486.

5. Lee J, Nunn J, Wright C. Height and weight achievement in cleft lip and palate. Archives Disease in Childhood. 1997; 75: 327-329.

6. Ranalli DN, Mazaheri M. Height-Weight growth of cleft children, birth to six years H.K cooper institute for oral-facial anomalies and communicative disorders. Lancaster, Pennsylvania. 1975.

7. Sahar F, Eman A. Growth status of Saudi Patients with Cleft Lip and Palate. Saudi Med J. 2002; 23(7): 823-827.

8. Sun L, Li W. Cervical vertebral maturation of female children with orofacial clefts. The Cleft Palate-Craniofacial Journal. 2013; 50(5): 535-541.

9. Ross RB, Trotman. Craniofac growth in bilateral cleft lip and palate; age six years to adulthood. Cleft Palate Craniofac J. 1993; 30: 261-273. 
10. Mardiati E. Indikator maturasi fisiologis untuk perawatan ortodonti interseptif. Prosiding Temu IImiah Bandung Dentistry 9. 2012; 315-328.
11. Mardiati E, Soemantry ES, Haroen ER, Thahar $B$, Sutrisna B. The Relationship determination between menarche and the peak of skeletal maturation using hand wrist and cervical vertebrae index. Dental Journal. 2014; 47(2): 67-71. 